\title{
THE RELATION BETWEEN TOWN PLANNING AND THE WORK OF PUBLIC CLEANSING*
}

It might not be evident at first sight that there was any very intimate connection between Town Planning and Public Cleansing. These two necessities of urban existence in one respect, at any rate, might be considered to be at the opposite poles: that is to say, as regards their apparent urgency. Town Planning may be, and frequently is neglected for long periods before people are aware that they are laying up trouble for their descendants. Take, for example, the small country town whose growth from a village has been so leisurely that to plan out roads and extensions looks like a needless prying into the future. There is no traffic problem: the country roads form the street net; the mediaeval market-place is amply spacious for a civic centre ; the open country is at hand for recreation: and as new houses are wanted they are simply added, one by one, like a duly growing family, to stand beside their elder brothers and sisters. But a closer scrutiny of this little typical slowgrowing town will show that it has its own housing problem bequeathed to it from a past when town planning was not in existence. At right angles, off the broad, main roads, open narrow mean passages, and on to these face meaner cottages, of later date than the houses on the street front, and lacking their fine architectural character. These cramped courts represent the attempt to grow quickly without control or due foresight, in order to cope with some sudden access of prosperity-whether a reflection of the industrial revolution, or some similar cause. No plan of development was prepared, and the simplest and most economical way of quadrupling the number of houses in the town was by developing the gardens at the backs of the main street frontages; a frequent additional preventive of more rational growth was the common land which began at the bottom of the garden plot and which, without a town plan to demonstrate its requirement for houses, was left untouched.

Or, in contrast to this slow-growing rural town with its method of increase by filling up and intensively developing the ample house plots, take the mushroom town of the Industrial Revolution itself. Here the growth was too quick: thousands of houses must be run up at onceworkers and boxes to put them in are all that can be thought of ; bye-laws may eventually control the individual house ; the existing country roads

\footnotetext{
*A paper read at the Annual Conference of Cleansing Superintendents at Sheffield, June, 1920.
} 
will preserve some sort of access to the centre ; each man has a back-yard, all the roads are fairly wide; what more can anyone want?

It is easy to see how, in the mellow-ripening rural fruit and in the rank-growing industrial fungus, town planning is neglected and for a while, it would seem, with impunity.

But no one can for long neglect Public Cleansing with impunity: the human nose, at any rate in this country, is more easily worked up to an indignation than the human eye. A dismal-looking street, a blackened atmosphere, a total absence of civic grandeur will not rouse us as effectually as an unscavenged kennel or an open pestiferous sewer. There can be no doubt that in the matter of Public Cleansing we in this country were more early civilised than in any other-just as in Town Planning we have lagged behind the rest of Europe. It was this instant appeal to the practical man, who always requires an immediate result, that set us early to work to render our towns sweet and clean : excepting as regards the grime of coal dust which we have tolerated, one supposes, under the impression that its mineral dirt is more respectable than vegetable decay or animal filth.

So you have the contrast between the remotely apparent advantages of Town Planning and the immediate necessity for Public Cleansing; and it was not until the latter phase of urban existence had been reduced to a science and almost a fine art that we began dimly to realize the need for the scientific planning and the artistic designing of our cities.

It is worth remembering that the exact converse is found in certain other countries: the writer was once visiting a foreign capital in the month of May, when the acacias, with which the noble streets were plentifully planted, were in full bloom. That city is, with the possible exception of Paris, the most beautiful and most elaborately planned in Europe ; but it certainly detracted from the enjoyment of its sunny beauty to have mingled with the sweet perfume of the acacias a lethal whiff which suggested that this fairy superstructure was erected upon a quaking bog of uncleanness.

An even more remarkable example of this inversion of our practice is Llasa, the capital of Thibet. For magnificence no other city in the world can compare with it: a noble Acropolis of sublime architecture : exquisite parks and gardens duly interposed between the different wards ; an encircling boulevard forming a holy processional way; an elaborate system of zoning: it sounds like the synthesis of the town planner's art. But a description of the sanitary state of the town would be perhaps more than even a Congress of Public Cleansers could stomach! It is perhaps only necessary to mention that burial consists in flinging the dead bodies out into the public places to be devoured by dogs, pigs and 
vultures, and that the refuse heaps in the streets are frequently as lofty as the houses.

Llasa exhibits to-day what must have been the condition of some of the magnificent cities of antiquity, though we know that the Romans, with their insistence upon a plentiful supply of fresh water, had laid the foundation of the sanitary town: fire and water being the two prime agencies of public cleansing.

Few people would hesitate as a place of residence between Llasa, palatial but pestiferous, and an English town such as Sheffield, illplanned, but well-cleansed. There is, however, just this much to be said on the other hand: a few of our sanitary experts let loose upon Llasa would soon turn it into a sweet and wholesome city, at no outrageous cost and without pulling the town to bits in the process. But to remodel a city that has been built without plan, dignity or convenience, is a task to daunt the boldest. Could Sheffield be made attractive as easily as Llasa could be rendered sanitary?

These vague speculations may serve to suggest that it is desirable to have your permanent structure well-designed, since no amount of scrupulous cleanliness can remedy deficiencies, though palliating their effects. A town that was designed purely with a view to ease of cleansing might not be otherwise entirely satisfactory. What, from this point of view, could be more desirable than the back-to-back house? If you look at some modern examples of these, you will note the absence of back yards, those frequent repositories of dirt: everyone has his back at the front door, as it were, and there thus is an intense inducement towards neatness and cleanliness ; the clothes' line suspended from house to house being, with their bunting display of clean linen, picturesque rather than untidy. A town built upon this model would be ideal for purposes of Public Cleansing; nothing could be concealed from the eagle eye of the sanitary official, even the gullies are exposed and the dust bin admirably accessible. But otherwise we know the structure is entirely wrong; and other considerations, through ventilation, space about buildings, etc., produce complications of site planning which, while rendering the task of the public cleanser more difficult, must be accepted by him as forming the premises upon which he has to base his system.

It is in this matter of disposition of house on site and relation of house to road access that the two spheres of Town Planning and Public Cleansing come into closest contact, rather than over the wider features of civic design. And as site planning in connection with Housing Schemes is so insistent at the moment, it is worth while considering briefly some of the different methods by which access to the back of the house can be obtained for the purpose of ashbin removal and the 
delivery of coal : two processes that are closely related, seeing that it is clear that if you bring a certain volume of substance into the house, even though it be consumed by fire, there will always be a residue to take away. In addition, there is the provision of fertiliser to the garden.

Now let us consider for a moment the ordinary method practised under the bye-law type of town development: a back passage or narrow road is provided giving direct access to every yard or back garden. This method, now generally discredited, has much to recommend it, however. There is, of course, the expense of an additional road: the extra policing and lighting required, and above all, the depression of these narrow, brick-sided ginnels. But the alternative offered in the London area is a particularly crude one : the passage is merely eliminated, and all carriage of ashes and coal done through the front door. This method probably arose first in the crowded city, where land is too valuable to give up to back access, and where a basement entrance from the front street did, at any rate, avoid carrying the dust-bin through the vestibule. But we have seen it transferred to suburban developments and perpetrated in a garden village, where neither of these justifications was present. The back passage is infinitely preferable, and in modern garden development, lightly paved and with hedges on either side, in place of dreary brick walls, some of its disadvantages disappear. But here another factor enters in : the new method of giving houses one-twelfth acre of garden and attaching the garden to the house, coupled with the high cost of roadmaking, even when the old-fashioned specification is relaxed for non-traffic roads-these combined factors have produced a long narrow plot (its width dictated, of course, by the plan of the house). So that for the collection of refuse and the delivery of coal the whole length of the garden has to be traversed, adding some 16 yards per house to the distance covered in the old back-yard type: multiply these 16 yards by the whole number of houses in your new quarters of the town and you have a very considerable addition to the labour-especially as this is in the hand stage of the carrying.

To meet these three objections-the crudeness of the metropolitan absence of method: the expensiveness and dreariness of the back passage: the length of the new gardens-five solutions have been offered. Before examining them, it is well to repeat that nothing is more foolish or shorter sighted than to condemn old methods by reason of certain defects perhaps more obvious to ourselves than to those who originated them-or perhaps only appearing when units, sound in themselves, are multiplied indefinitely: to condemn, on these grounds, without enquiring into the merits which the systems possessed: let us rather, in our new solutions, while correcting these errors, attempt to include their sound 
features. The bye-law suburb-that result of an exhaustive process of natural selection-contains many such features which the earlier garden suburbs neglected to their no small detriment : a reasonably level ceiling to your bedroom, for example, instead of a study in angles, slopes, valleys, and promontories. And in this matter of the back service to the house, the old method was extremely efficient, if somewhat expensive and not particularly attractive! Enthusiasts seeing something ugly are rather apt to fly to its opposite, which may be attractive but is not always particularly convenient.

The First solution gives a separate back approach and puts it between the back-yard and the garden: the gardens are then thrown into a quasi-allotment area, there being no particular division between the plots. If this road between yard and garden is the ordinary $9 \mathrm{ft}$. 0in. cart-way, it becomes doubled in length as compared with a single passage dividing the plots at the bottom of the gardens. But to avoid this, a footpath only is used, with a cart-way limited to a short approach between the houses. The dust-cart backs into this, and the bins are then collected along the footpaths by means of hand trolleys. Port Sunlight has been planned according to this method, and like everything else there, it is extremely efficient: the dust-bin collecting and coal delivery is direct and clean, and the garden space can be allotted precisely according to the requirements of the separate householders: in equal plots if they are all keen gardeners-or in varying areas: there is no waste land attached to a house where a garden is not wanted. But there is the perpetuation of the enclosed yard, with the unattractive outlook to the kitchen

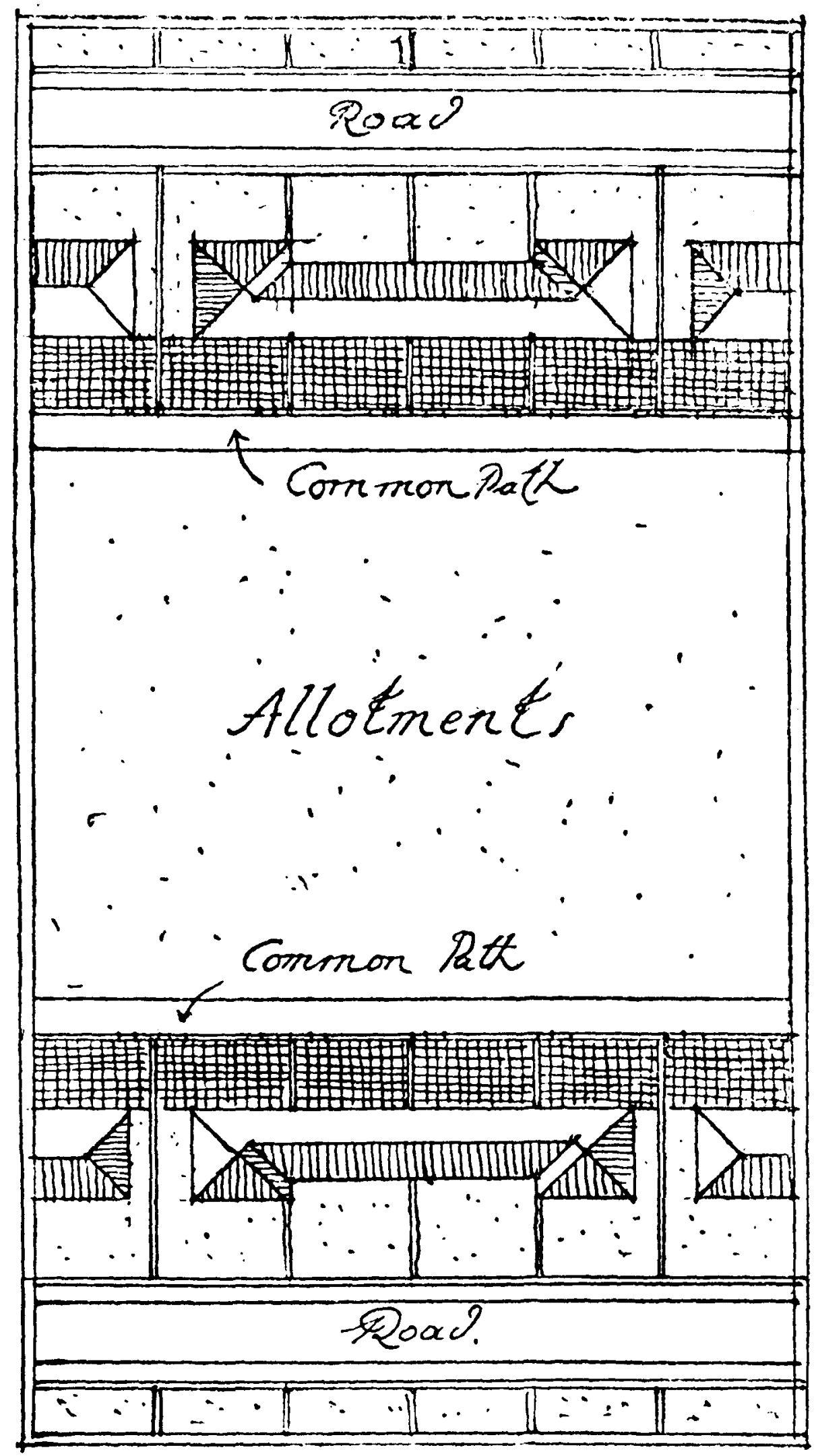

1. Direct back access by paths. or through-lit living room; if, however, the back wall to the yard were converted into a trellis to give a glimpse on to the garden space beyond, the privacy would be lost-as, of course, the footpath is common to the world. 
at large. The writer is not one of those who consider that there should be no privacy whatever at the back-door : there are certain homely operations and certain housewifely costumes which are more seemly to all parties, onlooker and operator alike, if veiled from public gaze. But the chief objection to this type of plotting is the separation of the garden from the house. This is cheerfully put up with when houses have no gardens near, and an allotment must be obtained at some distance. But after all, a garden is not purely a vegetable patch-it has its recreative uses-it is not necessarily

\section{"retired leisure}

That in trim gardens takes its pleasure."

The family party taking tea on the allotment is making the best of a bad job: the orchard at the end of the garden, reached by a footpath direct from the house, has more the air of being part of a considered

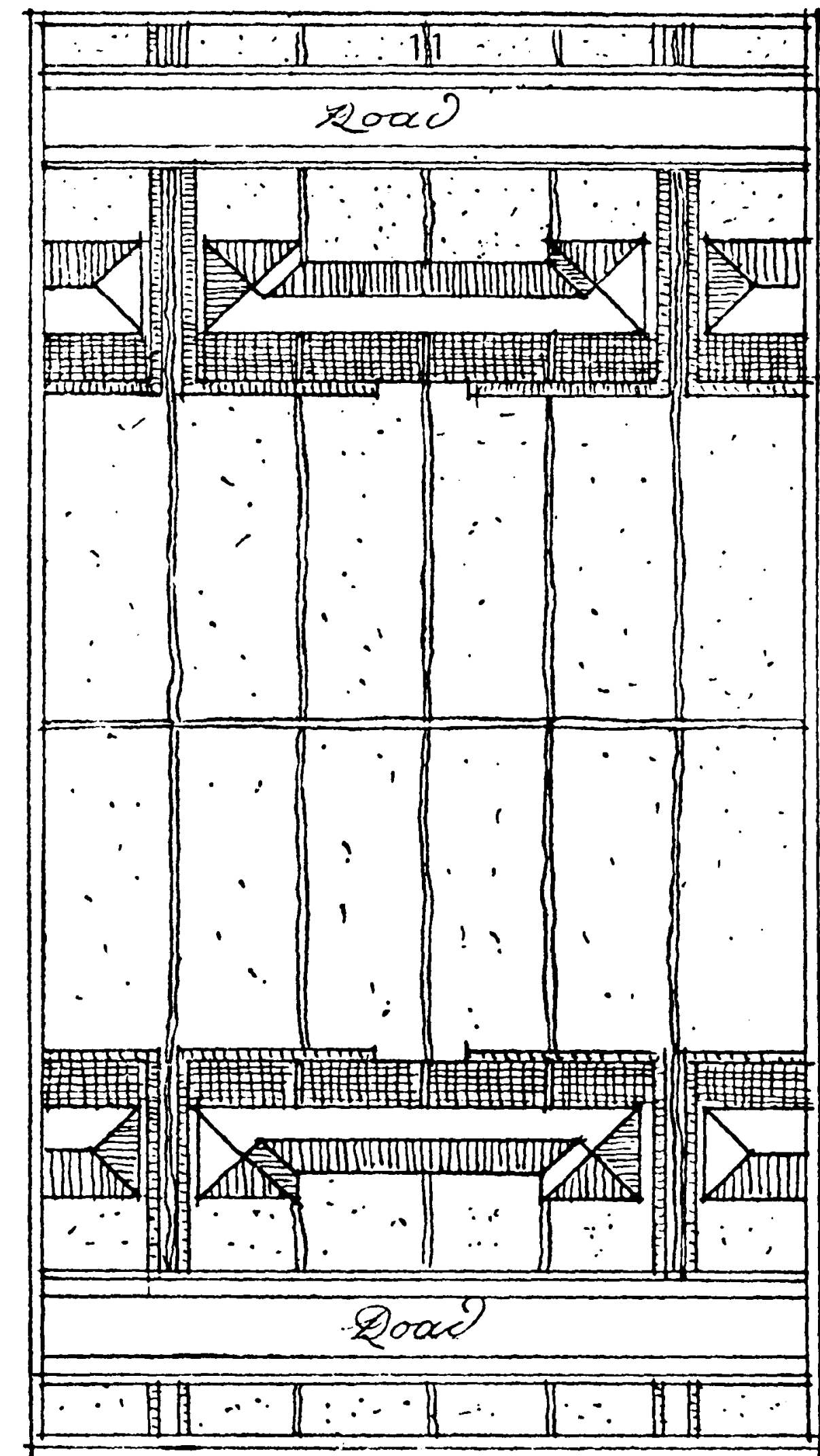

2. Access to central houses past backs of end houses. scheme of existence. The very essence of a garden, as its name implies, is an enclosure : a space framed apart from the world by means of its hedge; and if you are going to frame your picture, it is worth having a real structural frame, not a mere "passe-partout."

The Second solution aims at modifying this garden defect and also at reducing the cost of the back road: in this case each terrace of houses, whether of $4,6,8$ or 10 , is taken separately, and the backs approached round the end houses: the central houses are reached by passing the backs of the end and intermediate houses ; there are no enclosed backyards; the paved square at the back gives directly on to the garden; and the path between is quite private to each house except in so far as it is used for collecting the dust-bin or delivering the coal or the garden manure. It is said that great men have no secrets from their valets, so it might be suggested there is no domestic privacy to the dustman. But a method 
of this sort requires a good deal of neighbourly feeling for it to work pleasantly, and it is worth noting that the Sheffield people have reached this high pitch of communal life, for it may be seen in successful operation in that city. But it is not a system that can be recommended as a general rule, the risks of dissatisfaction are too great.

The Third solution is also one for special rather than usual use. It aims at giving a back and front access, but reduces the front road to a path, whereas the back road provides all the wheeled access to the house, and is somewhat wider than the usual back passage. At Bradford, where this system is permitted under the bye-laws, this road is required to be 20 feet in width. The long gardens are placed in front of the houses, and there are merely yards behind. This is an interesting type of development, and one which gives the advantages of the old method to the dust collector, without the cost of the front roads. But it is a drawback that all cavalcades must approach the house by the back door, weddings no less than funerals, unless, as at Bradford, comparatively short lengths are allowed with direct, access at either end to traffic roads ; in which case the path between the gardens might not be found too long. This method may well be attempted where the houses face east and west and where it is not necessary to face any living-rooms on to the enclosed

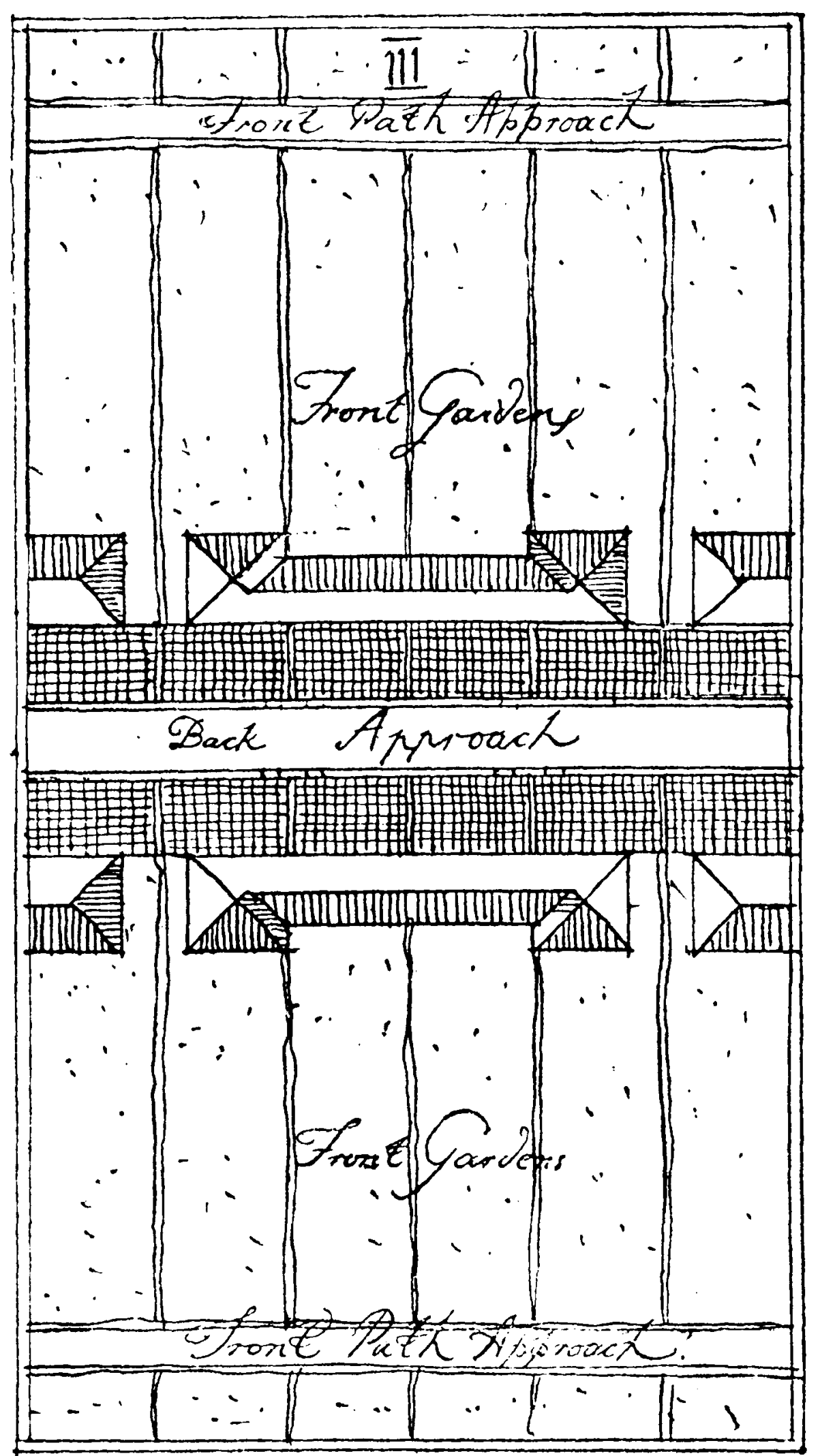

3. Direct back ancess by service road. yards; and where, for special reasons of levels, it is desirable to keep the house fronts far apart.

The Fourth solution is one with which everyone is familiar, as it has been encouraged by the Ministry of Health in the post-war Housing Schemes. Here the access to the intermediate houses in a group is provided by an internal tunnel shared by two houses. All clearing work is done direct from the front of the house : as against the saving in the back road has to be reckoned the cost of the tunnel, which must be wide 
enough to admit a wheelbarrow. The extra space caused by the passage can be made use of upstairs to give larger bedrooms, or with some types of plan it is possible to provide in one of these central houses four bedrooms: thus, in a block of four houses, one has the extra bedroom. It is sometimes objected that this passage is liable to nuisance; but it must be remembered that it is not common property, but belongs jointly to two houses, and can only be entered by crossing the front garden. At the same time, disputes might arise between the neighbours as to who was responsible for keeping it clean. The town of Leicester has for long permitted these tunnels, and they appear to work well.

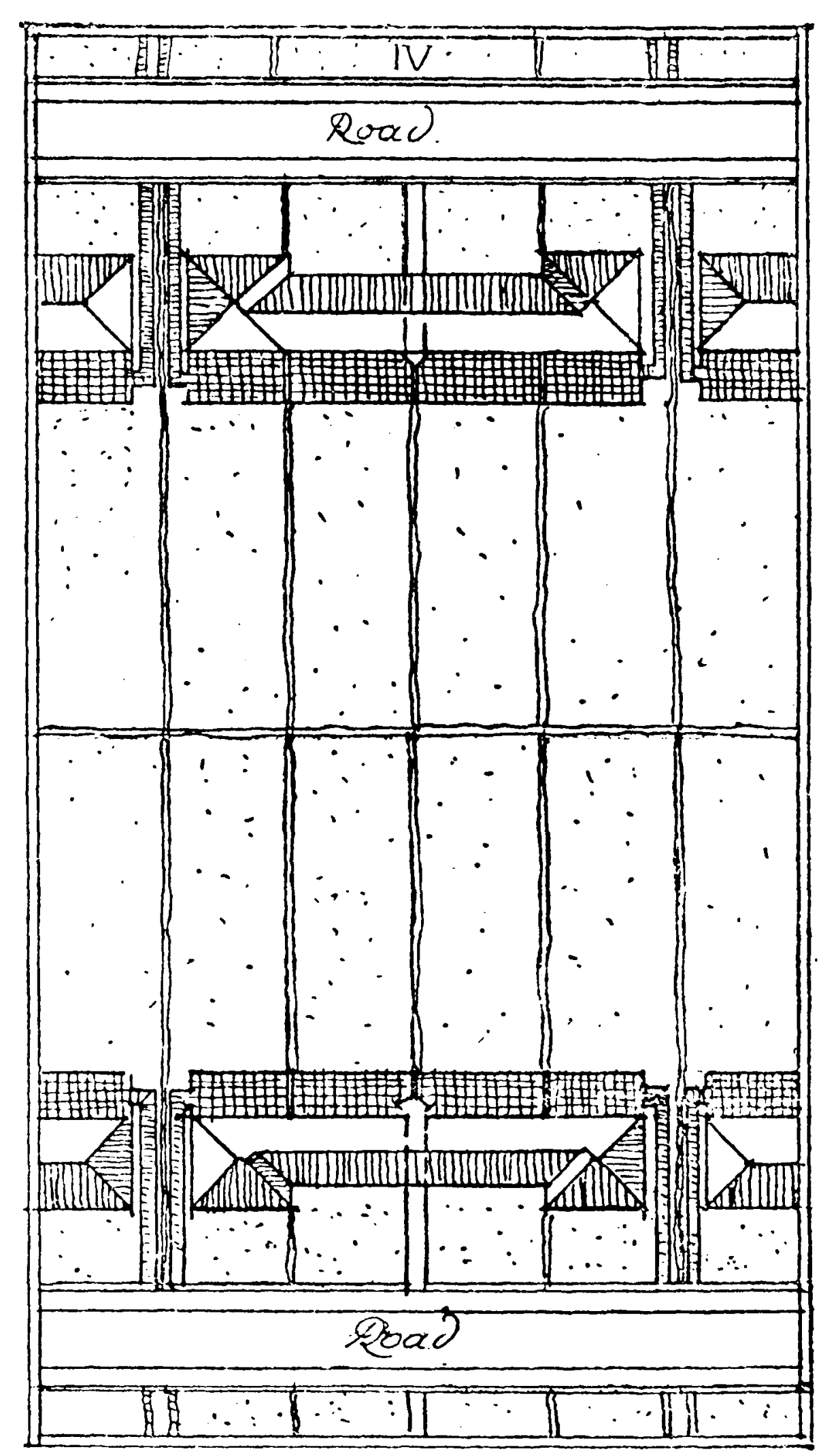

4. Access to central houses through tunnel.

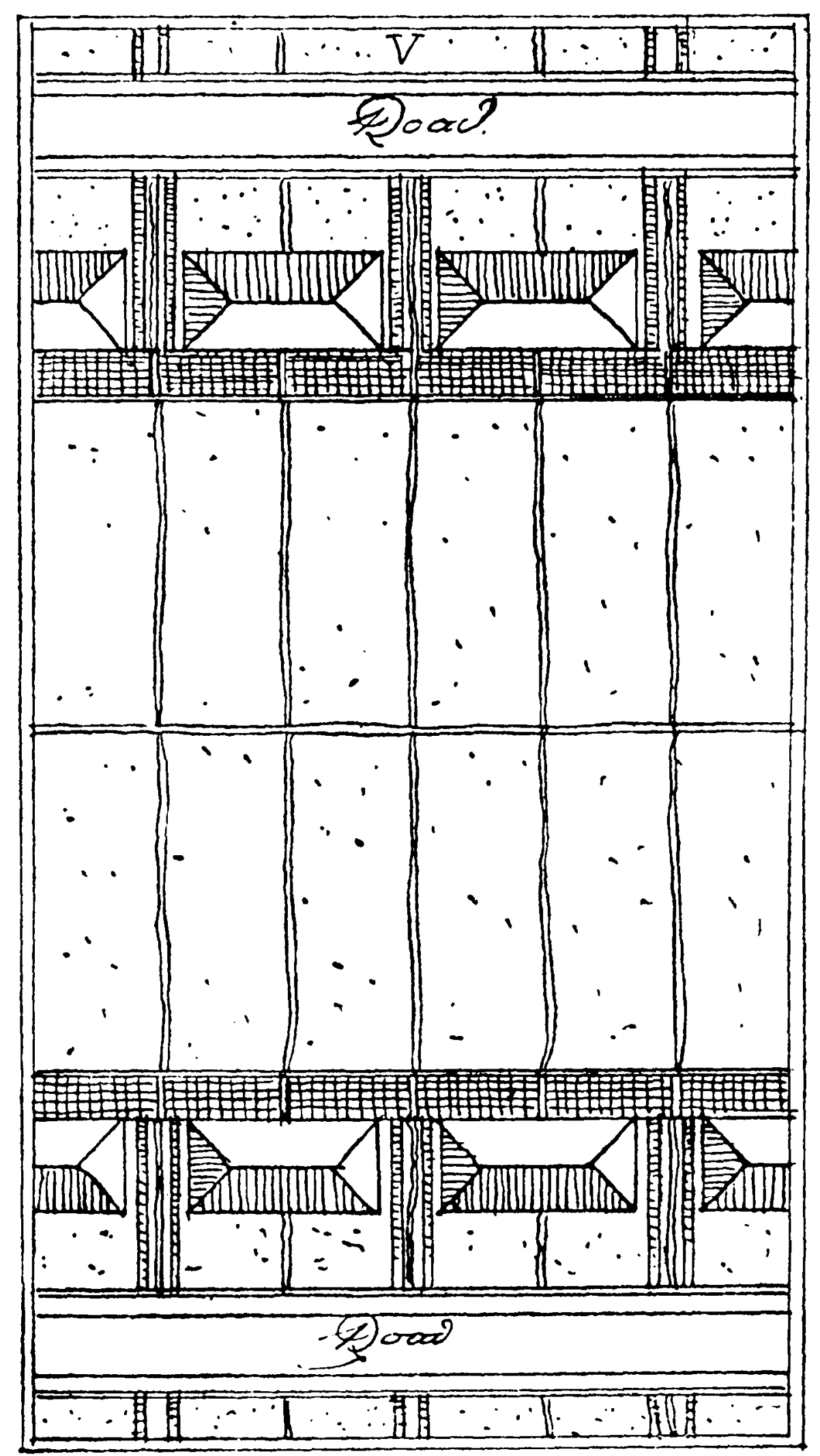

5. All houses with side access.

In several of these foregoing methods it is evident that the end houses present no difficulties, and the $F$ ifth solution provides only end houses-or in other words semi-detached grouping. This is at once the simplest and probably the most effective way of disposing the houses on the site for 
this and many other purposes. As compared with four blocks, the cost of the central tunnel is saved, but there are two additional external end walls and more road frontage is taken up per house. There is also a monotonous effect about endless semi-detached blocks which do not give any opportunity of interesting grouping.

The advantages of the semi-detached are, however, very great, and the occasional use of a four block, if skilfully placed, can be made to introduce the necessary variety of mass.

In these last two methods, and in the Sheffield example, all the collecting is done from the front road, and the important question arises as to who is to bring the bin from the back of the house. There are several cases where this has to be done by the householder; but if these systems are to be encouraged, arrangements should be made for the collector to do all the handling of the bins.

It might be said that all these are details of estate development, and that they hardly affect town planning. But after all; the planning of these units ultimately affects the whole town, and it is the function of the town planner to visualise the effect of their manifold multiplication ; the other factors of town existence have also to be considered and a solution discovered which harmonises so far as possible all the requirements. It is the duty of the town planner, for example, to put before the public cleanser the logical results of the limitation of houses to the acre now being adopted. The residential area will cover twice or three times as much ground. This may not be noticed with a few houses, but when it becomes a normal method of town growth the greater distances to be traversed will certainly add to the cost of the municipal services.

The housing schemes which are now being built throughout the country will give an opportunity for testing a great many novel forms of estate development and town planning on a large scale. We have been usually dependent before for experimental work on small examples, often the work of enlightened private enterprise, in which it had been extremely difficult to gauge accurately the results from every point of view. It is to be hoped that when these houses are in occupation and the new districts that they occupy are being administered, conferences of technical experts similar to Public Cleansers should meet to discuss the effects of this new form of town development in operation.

Such features as the tidiness of the new streets will then come up for discussion: the desirability of many of the grass margins which we are showing or whether we are disposing these grass margins in the most suitable streets : for example, one feels that unless a grass margin can be at least eight feet wide it is better omitted : and that anyhow a grass margin should never be shown in a main traffic road, but reserved for 
a wide avenue of a more boulevard or promenade type. But a mere opinion needs verification by the actual usage of such streets ; and we shall no doubt find the conditions of grass margins in a semi-private suburb like Hampstead is no adequate criterion of the wear and tear of a similar margin in a municipally constructed suburb of a northern industrial town.

Again, the cul-de-sac, which figures so frequently in housing schemes, is an untried feature as regards general use. The turning spaces that are shewn vary very much in size- the Government Manual had been very discreet in figuring these - and it is likely that some of the first furniture vans may give some practical lessons on the space required. The extent also to which through communication by means of footpaths is required from these culs-de-sac is not always fully realised, and in a word, their general desirability from the point of view of tidiness and inspection. They originated, we know, from a sound desire to economise in road construction; but it would be a bold man who could claim to have visualised all the side issues of their actual usage. And at any rate this is an interesting example of the use of a feature which, under the older practice of town growth and administration had been condemned wholesale, but which has been revived by town planners without, it is hoped, its objectionable features.

It would be very desirable that such discussion did not take place sectionally-but that all those concerned in the planning and administration of cities: general town planners, medical officers, highway authorities, housing architects, park superintendents, public cleansers, lighting, drainage and water experts, etc., not forgetting among this crowd of experts some representatives of the inhabitants, should meet together, and with the utmost frankness appraise the working value of these experiments. There can be no doubt that town planners, at any rate, would learn a great deal from the constructive criticism which such a conference would produce.

The spirit of co-operation is what is required: the old view is long exploded that provided your houses are sanitarily designed, your refuse collected, your sewage carried off and your streets scavenged, your town can look after itself : in addition, its traffic must be provided for and its inter-communications safeguarded; its area zoned or districted, in the interests of economic development and amenity, which means that factories (among which one might include dust destructors) are no longer free to plant themselves in the midst of housing areas, to shadow them in gloom ; and finally, the quality of Civic Design must permeate the wholeleavening the lump -and lifting it on to a plane commensurate with the dignity of our civic greatness.

Patrick Abercrombie. 
Plate 48

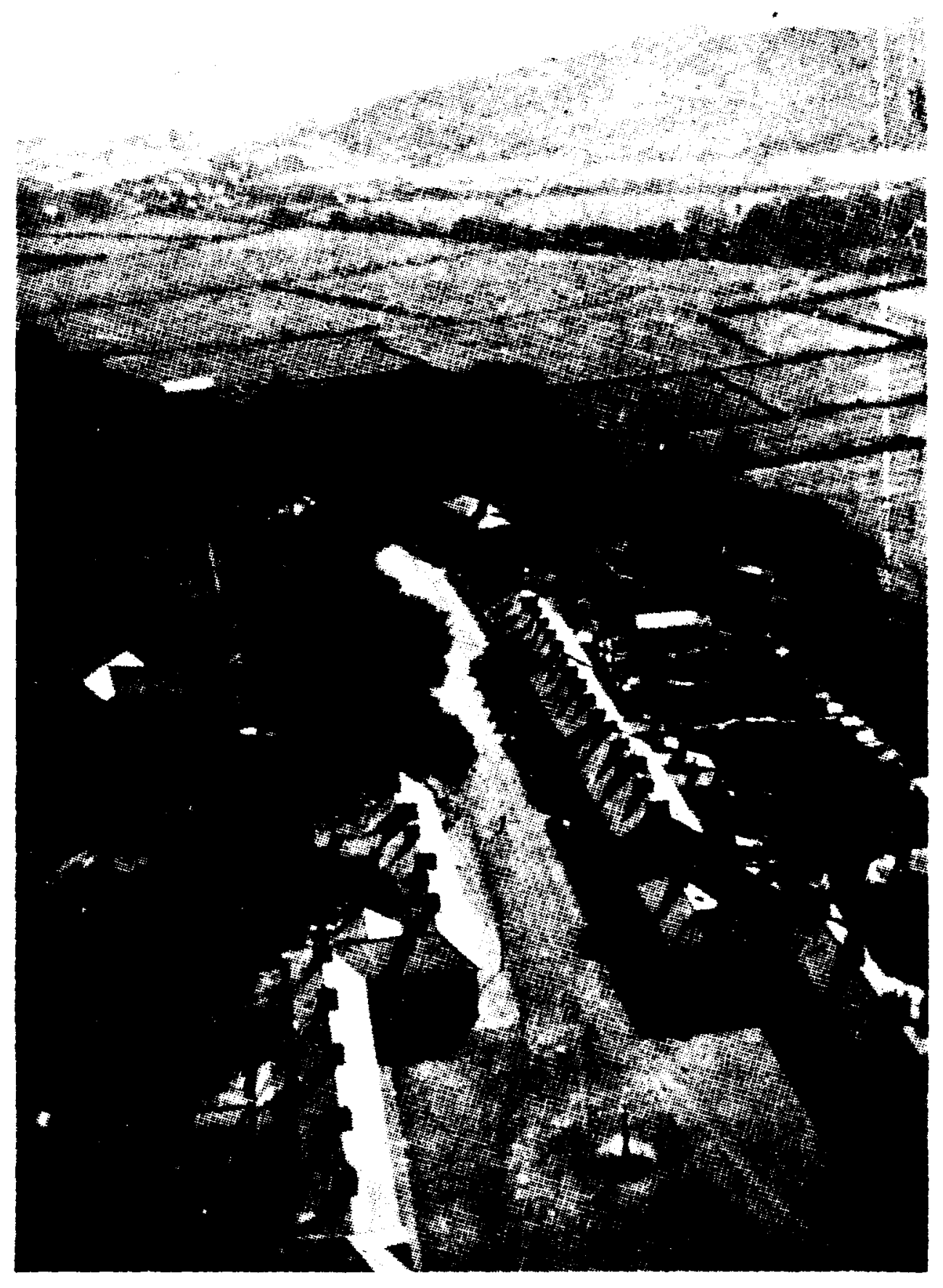

Vie'w from hilltop

along approach road

TREMADOC 